\title{
Characterization and Anticancer Potential of Silver Nanoparticles Biosynthesized from Olea chrysophylla and Lavandula dentata Leaf Extracts on HCT116 Colon Cancer Cells
}

\author{
Noha Moslah Al Sufyani, ${ }^{1}$ Nahed Ahmed Hussien, ${ }^{1,2}$ and Yousef Mohammed Hawsawi $\mathbb{D}^{3,4}$ \\ ${ }^{1}$ Biology Department, Faculty of Science, Taif University, Al-Hawyeia 888, Saudi Arabia \\ ${ }^{2}$ Zoology Department, Faculty of Science, Cairo University, Giza 12613, Egypt \\ ${ }^{3}$ Research Center, King Faisal Specialist Hospital and Research Center, Jeddah 21499, P.O. Box 40047, Saudi Arabia \\ ${ }^{4}$ College of Medicine, Al-Faisal University, P.O. Box 50927, Riyadh 11533, Saudi Arabia
}

Correspondence should be addressed to Yousef Mohammed Hawsawi; hyousef@kfshrc.edu.sa

Received 14 October 2019; Accepted 4 December 2019; Published 20 December 2019

Academic Editor: Hassan Karimi-Maleh

Copyright @ 2019 Noha Moslah Al Sufyani et al. This is an open access article distributed under the Creative Commons Attribution License, which permits unrestricted use, distribution, and reproduction in any medium, provided the original work is properly cited.

\begin{abstract}
Cancer was ranked as the second leading cause of death, and colon cancer has been reported as the third most frequent cancer worldwide. Chemotherapeutic drugs act on normal and cancerous cells similarly; therefore, they have various adverse side effects. Nanoparticles were identified to have a controlled effect on different cancer cell lines. The present study is aimed at studying biosynthesis silver nanoparticles by using aqueous Olea chrysophylla and Lavandula dentata leaf extracts, separately, and evaluating their anticancer potential. Silver nanoparticles were characterized by using SEM, XRD, FTIR, zeta potential, and size distribution mean, and their antiproliferative and apoptotic potentials were evaluated on HCT116 cells. Results show the formation of silver nanoparticles Olea-AgNPs and Lav-AgNPs due to the change of color to dark brown, and characterization revealed their crystalline shape with a mean size of $284.5 \mathrm{~nm}$ for Lav-AgNPs and $328.6 \mathrm{~nm}$ for Olea-AgNPs. Lav-AgNPs shows more stability than Olea-AgNPs due to its higher negative zeta potential $(-14.3 \mathrm{mV})$ than nanoparticles biosynthesized from Olea leaves $(-0.877 \mathrm{mV})$. Conversely, Lav-AgNPs shows more effective antiproliferative potential on HCT116 with $(\mathrm{IC} 50=59.79 \mu \mathrm{g} / \mathrm{ml})$ than Olea-AgNPs $(\mathrm{IC} 50=99.35 \mu \mathrm{g} / \mathrm{ml})$. However, Olea-AgNPs significantly increased the late stage of apoptotic and necrotic cells in comparison to Lav-AgNPs-treated cells in flow cytometry assay. Silver nanoparticles biosynthesized from Olea and lavender show anticancer potential with a more effective potential reported compared to Lav-AgNPs.
\end{abstract}

\section{Introduction}

In recent years, cancer was ranked as the second leading cause of death that leads to about 9.6 million deaths in 2018 worldwide. There are different types of cancer based on the invaded tissue, but the most common cancers are as follows: lung, breast, colorectal, prostate, skin, and stomach cancers $[1,2]$. According to the WHO, the global burden of cancer is expected to increase by the year 2040 to 27.5 million new cases and 16.3 million deaths as a result of population growth and aging [1]. In Saudi Arabia, cancer is very common due to the high rate of consanguinity and genetic factors $[3,4]$ as it has been ranked as the second leading cause of deaths.
Colon cancer is the third most prevalent cancer worldwide and defined as a carcinoma that affects the lining of colonic mucosa. The disease occurs as a result of tumor suppressor and/or oncogenic gene mutations that in turn leads to polyp's generation and eventually adenocarcinomas [5-7]. There are many toxic side effects that have impact on colon cancer patients due to the use of chemotherapeutic drugs because those drugs do not distinguish between normal and cancerous cells [8-10].

Nanoparticles were reported to have a controlled effect on cancer cell lines; therefore, they have the potential to be used as an important therapeutic anticancer drug. There are different methods to synthesize nanoparticles as chemicals 


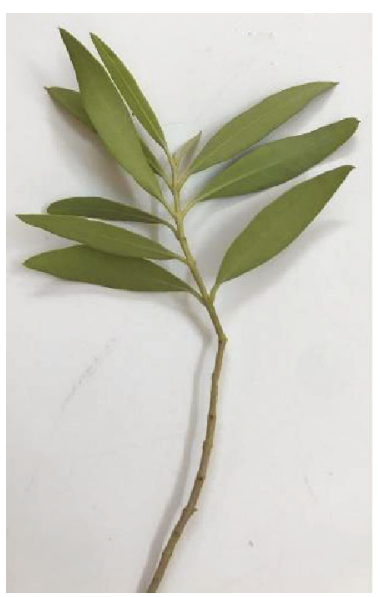

(a)

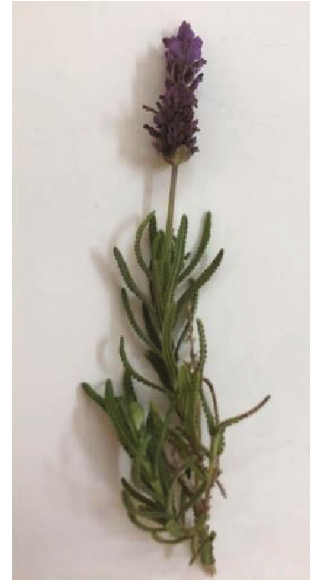

(b)

Figure 1: Collected Olea europaea (a) and Lavandula dentata leaves (b).

which include flora-based extracts and microbial process. However, plant extract-based synthesis is the best method with low-cost, less adverse effects and it represents a standard candidate for large-scale production [11, 12].

Several researches have been reported to have the ability to synthesize various nanoparticles including silver using plant extracts $[13,14]$. Plant extracts are characterized by the presence of hydrogenase and reductase enzymes and various phytochemicals such as flavonoids, terpenoids, phenols, and dihydric phenols although they act as reductants in the presence of metal salt to synthesize nanoparticles [15-17].

In the present study, we collected olive and lavender leaves from Taif Province in the western region of Saudi Arabia. In Taif, more than 261 different plant species were identified and around 165 of these plants were reported with high potential to be used as a therapeutic agent [18] including olive and lavender.

Olive plant belongs to the family Oleaceae, genus Olea, and species europaea; however, there are various subspecies that are found worldwide. Olea chrysophylla was found to be distributed from East Africa to the Kingdom of Saudi Arabia (KSA) [19-21]. Olea as an important example of phenolic compounds exerts many various physiological properties, such as antioxidant, anti-inflammatory, antimicrobial, anticancer, cardioprotective, and more [22-24]. The protective and therapeutic potential of olive plant was referred to oleuropein and its derivatives including hydroxytyrosol and tyrosol; moreover, it contains caffeic acid, p-coumaric acid, vanillin, rutin, luteolin-7-glucoside, apigenin-glucoside, and diosmetin-7-glucoside [25].

Lavender (Lavandula dentata $L$.) is a widely distributed plant cultivated in the temperate climates. The extract of the different parts of lavender contains different components such as geraniol, linalool, linalyl acetate, ursolic acid, and others that are used in toiletry, pharmaceutical, food, and flavor industries. Importantly, lavender has various medicinal applications including the treatment of skin sores, pain, inflammation, rheumatic, gastrointestinal, and nervous disorders [26].
The present study was aimed at adding a bioreduction process of silver nanoparticles using aqueous Olea chrysophylla and Lavandula dentata leaf extracts, separately, and characterization of the biosynthesized silver nanoparticles and at reporting their apoptotic and anticancer potentials towards HCT116 human colon cancer cells.

\section{Materials and Methods}

2.1. Preparation of Olea chrysophylla and Lavender Leaf Extracts. Olea chrysophylla and lavender leaves were collected freshly from Al Shafa area in Taif City, Kingdom of Saudi Arabia (KSA) (Figures 1(a) and 1(b), respectively) and then rinsed in water before dryness away from sun. Dried leaves were ground in an electric grinder to obtain fine powder. Fifty grams of each leaf powder was mixed with $500 \mathrm{ml}$ of sterile distilled water and boiled for about $10 \mathrm{~min}$. Leaf extracts of both Olea and lavender were kept in room temperature to cool and then filtered with a Whatman filter paper and stored at $4^{\circ} \mathrm{C}$ for later use in silver nanoparticle synthesis.

2.2. Biosynthesis of Silver Nanoparticles. $10 \mathrm{ml}$ of each (Olea and lavender leaves) extract was mixed with $10^{-3} \mathrm{M}$ aqueous solution of silver nitrate $\left(\mathrm{AgNO}_{3}, 90 \mathrm{ml}\right)$ and heated in water bath $\left(80^{\circ} \mathrm{C}\right)$ with continuous stirring until there is change of extract color from pale yellow to dark brown that referred to the formation of $\mathrm{Ag}$ nanoparticles (AgNPs) by reduction. Olea-AgNPs and Lav-AgNPs were obtained by centrifugation of their extract with AgNPs formed at $15,000 \mathrm{rpm}$ for $10 \mathrm{~min}$, and then supernatants were discarded and pellets were washed 3 times with sterile distilled water and centrifuged to remove any adsorbed substances on the AgNPs surfaces. The purified pellets were left in petri dishes and dried in the oven at $60^{\circ} \mathrm{C}$ for $16-24 \mathrm{~h}$, and then dried Olea-AgNPs and Lav-AgNPs were scrapped out from the petri dish for the further evaluations. 


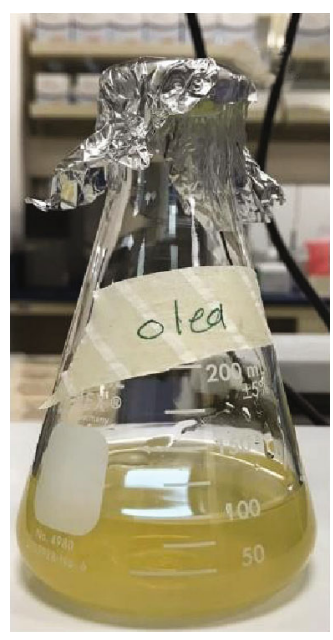

(a)

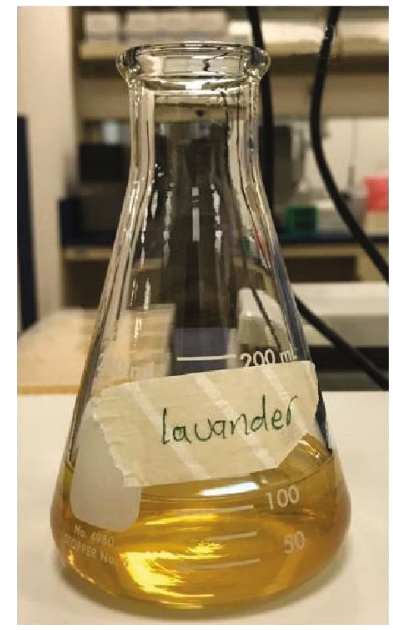

(b)

Figure 2: Extract product of Olea europaea (a) and Lavandula dentata leaves (b) showing yellow color.

2.3. Characterization of Silver Nanoparticles. A scanning electron microscope (SEM, JEOL instrument) was used to determine surface morphology of dried biosynthesized silver nanoparticles (Olea-AgNPs and Lav-AgNPs). However, the rest of biosynthesized nanoparticles were freshly suspended in $0.9 \%$ saline for further characterization evaluation. The size of nanoparticles and their surface charge were determined using a particle size analyzer (Zetasizer Nano ZS, Malvern Instruments Ltd., U.K.) at $25^{\circ} \mathrm{C}$ with a $90^{\circ}$ detection angle. The possible functional groups in biomolecules that are expected to be found in the Olea and lavender extracts were determined using Fourier Transform Infrared Spectroscopy (FTIR). An X-ray diffractometer $(30 \mathrm{kV}, 100 \mathrm{~mA})$ was used to perform X-ray diffraction (XRD) measurement on Olea-AgNPs and Lav-AgNPs to report its structure, and the spectrum was recorded by $\mathrm{CuK} \alpha$ radiation with a wavelength of $1.5406 \AA$ in the $2 \theta$ (from the range of $20^{\circ}-80^{\circ}$ ). The X-ray diffraction $(\mathrm{XRD})$ patterns were evaluated by OriginLab software and compared with JCPDS card no. 040783.

2.4. Cell Culture. Human colorectal cancer cell line HCT116 (from research center at KACST, Jeddah, KSA) was seeded into $75 \mathrm{~cm}^{2}$ flasks in RPMI-1640 (Gibco BRL, Grand Island, NY) supplemented with fetal bovine serum (10\%, FBS), sodium pyruvate $(1 \mathrm{mM})$, L-glutamine $(2 \mathrm{mM})$, and antibiotics (penicillin $100 \mathrm{IU} / \mathrm{ml}$, streptomycin $100 \mu \mathrm{g} / \mathrm{ml}$ ) under standard culture conditions $\left(37^{\circ} \mathrm{C}, 95 \%\right.$ humidified air and $5 \% \mathrm{CO}_{2}$ ). When cells become approximately $80 \%$ confluent, cells were subdivided and maintained.

2.5. Sulphorhodamine B (SRB) Assay. HCT116 monolayer cell culture was trypsinized and suspended in fresh medium (RPMI-1640 supplemented with $10 \%$ FBS) at a cell density of $1.0 \times 10^{5} / \mathrm{ml}$ and then plated in 96-well tissue culture plates (in 2 separate plates for Olea-AgNPs and Lav-AgNPs treatment). After 24 hours, the supernatant was flicked off after the formation of cell monolayers with $60-75 \%$ confluence, and then $100 \mu \mathrm{l}$ of serum-free media was added to the cells containing serial concentrations of Olea-AgNPs (70-
$200 \mu \mathrm{g} / \mathrm{ml})$ and Lav-AgNPs $(10-100 \mu \mathrm{g} / \mathrm{ml})$, on separate plates. The plates were then incubated at $37^{\circ} \mathrm{C}$ for 72 hours in a $5 \% \mathrm{CO}_{2}$ incubator with a microscopic examination daily. After 72 hours, the supernatant was discarded, and $150 \mu \mathrm{l}$ of $10 \%$ trichloroacetic acid (TCA) was added to each well. After incubation for one hour at $+4^{\circ} \mathrm{C}$, plates were washed with sterile distilled water $(\times 3)$ and then stained with $0.4 \%$ SRB in $1 \%$ acetic acid $(70 \mu \mathrm{l})$ and finally incubated at room temperature $(10 \mathrm{~min})$. Plates were washed with $1 \%$ acetic acid, air-dried, and then $10 \mathrm{mM}$ Tris base $\mathrm{pH} 7.4(150 \mu \mathrm{l})$ was added to the wells to solubilize the dye. The plates were shaken vigorously for $5 \mathrm{~min}$ and color absorbance was measured at $540 \mathrm{~nm}$ using an ELISA microplate reader.

Cell viability $\%=\left(A_{\text {treatment }}-A_{\text {blank }}\right) /\left(A_{\text {control }}-A_{\text {blank }}\right) \times$ $100 \%$, where $A$ is the absorbance. Then values were plotted in Microsoft Excel 365 to generate graphs, and then the Quest Graph $^{\mathrm{TM}}$ IC50 Calculator was used to detect IC50 concentration for Olea-AgNPs and Lav-AgNPs for further treatment.

2.6. Apoptotic Potential Evaluation by Flow Cytometry. Cells were treated with IC50 for both Olea-AgNPs and LavAgNPs separately, and then after 48 hours, the apoptosis of HCT116 cells was detected by flow cytometry. Briefly, the cells were stained with Annexin V-FITC and propidium iodide (PI) at room temperature (20 $\mathrm{min})$, and then live, apoptotic, and necrotic cells were analyzed by flow cytometry according to the instruction of the Annexin V-FITC Apoptosis detection kit (Nanjing KeyGen Biotech, China).

\section{Results and Discussion}

The change of color from pale yellow (Figures 2(a) and 2(b)) for Olea and lavender leaf extracts to dark brown (Figures 3(a) and 3(b)) after the addition of silver nitrate and heating indicates the formation of silver nanoparticles Olea-AgNPs and Lav-AgNPs, respectively. Scientific evidence suggested the synthesis of silver nanoparticles by using aqueous Olea europaea leaf extract due to the change of color from transparent to yellow, and they monitored pure $\mathrm{Ag}^{+}$ion 


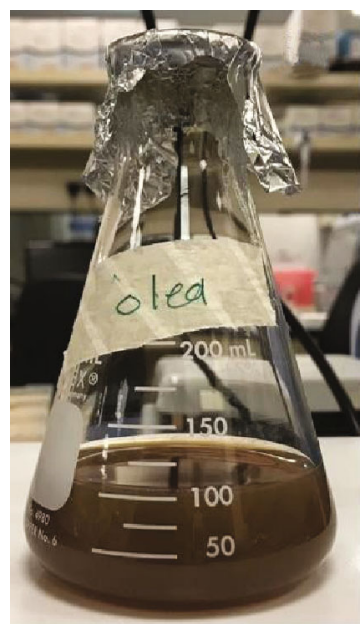

(a)

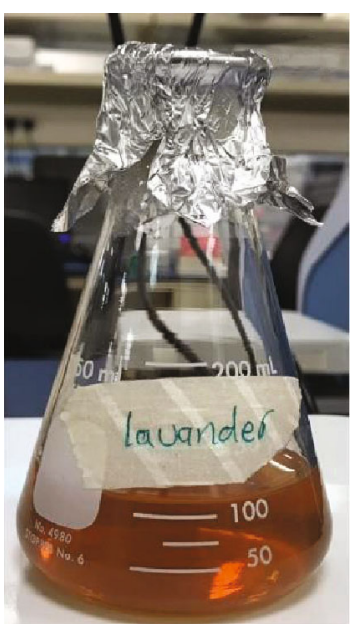

(b)

Figure 3: Change of color of Olea europaea (a) and Lavandula dentata (b) leaf extracts to dark brown color due to silver nanoparticle formation.

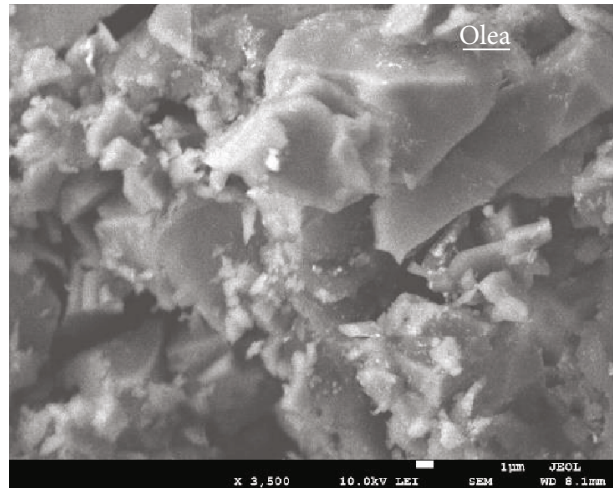

(a)

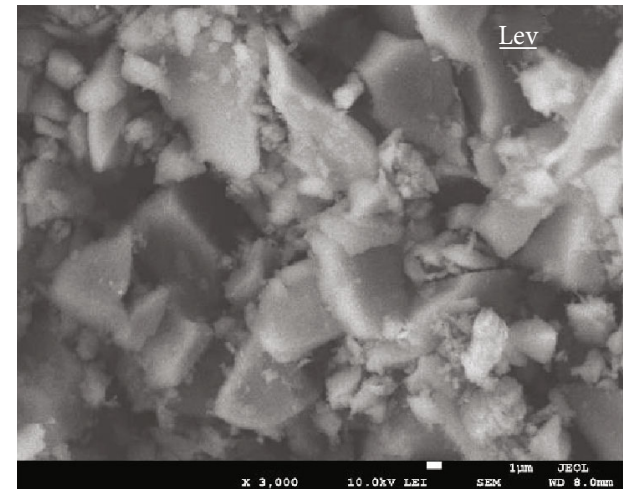

(b)

FIGURE 4: Scanning electron microscope photo for biosynthesized Olea-AgNPs (a) and Lav-AgNPs (b) showing their crystalline shape.

reduction to $\mathrm{Ag}^{0}$ by measuring $\mathrm{UV}$-vis spectrum of the reaction media at regular intervals [27]. In our knowledge, there is only one research succeeded in the green synthesis of silver nanoparticles using lavender leaf extract, they reported the change of colorless $\mathrm{AgNO}_{3}$ and yellow lavender extract to dark red. They proofed the direct bioreduction of $\mathrm{Ag}^{+}$to $\mathrm{Ag}^{0}$ and the formation of AgNPs by measuring UV-vis spectra that indicates the appearance of a single surface plasmon resonance band at $\lambda_{\max } 440 \mathrm{~nm}$ for the AgNPs; they conclude that this appears due to electron collective oscillation in the conduction band of AgNPs [28].

3.1. Scanning Electron Microscope and XRD Studies. The biosynthesized silver nanoparticles from Olea and lavender leaf extracts appeared in a crystalline shape as shown in Figure 4. XRD of Olea-AgNPs shows 4 sharp peaks at $2 \theta=$ $38.3^{\circ}$ (Ag 111 plane), 44.49 (Ag 200 plane), 64.6 (Ag 220 plane), and $77.5^{\circ}$ (Ag 311 plane). Those are standard peaks according to Bragg's reflection of silver nanoparticles that indicates the face centered cubic (FCC) crystalline shape of
Olea-AgNPs (Figure 5(a)). Moreover, there are 2 peaks that appeared at $32.25^{\circ}$ and $46.21^{\circ}$ (Asterisk) that are weaker than those of silver due to organic phytochemical compounds present in Olea leaf extract [29]. The XRD pattern of LavAgNPs shows the same peaks at $2 \theta=38.3^{\circ}, 44.49^{\circ}, 64.6^{\circ}$, and $77.5^{\circ}$, but they are not sharp intense as those of Olea-AgNPs. Figure 5(b) shows other sharp intense peaks at $2 \theta=27.90^{\circ}, 32.16^{\circ}$, and $46.00^{\circ}$ (Asterisk) that are referred to $\mathrm{AgCl}$ nanoparticles. Chloride ion was thought to be found in anthocyanins that was reported in lavender plant that are linked to the crystalline and amorphous organic phases of the formed silver nanoparticles [30]. Totally, XRD patterns reported in this study are in good agreement with other earlier research that reported silver nanoparticle biosynthesis using plant extracts.

3.2. Nanoparticle Size Distribution and Zeta Potential. Biosynthesized silver nanoparticles appear polydispersed in nature, with a size distribution mean of $284.5 \mathrm{~nm}$ for Lav-AgNPs and $328.6 \mathrm{~nm}$ for Olea-AgNPs as shown in 


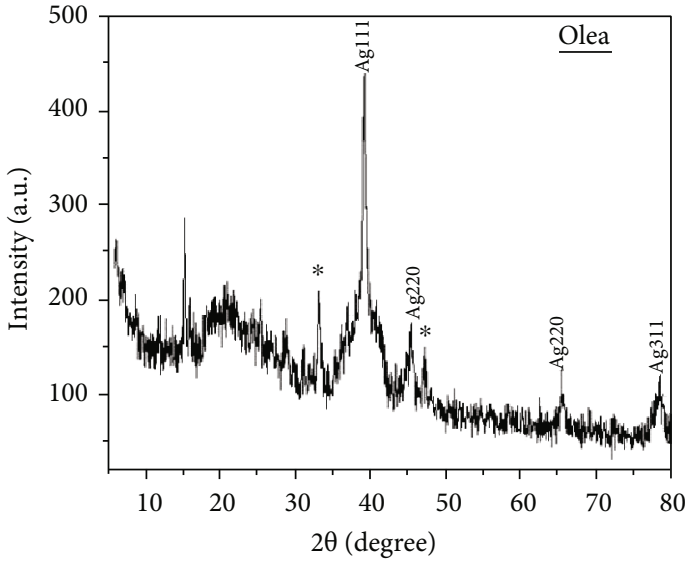

(a)

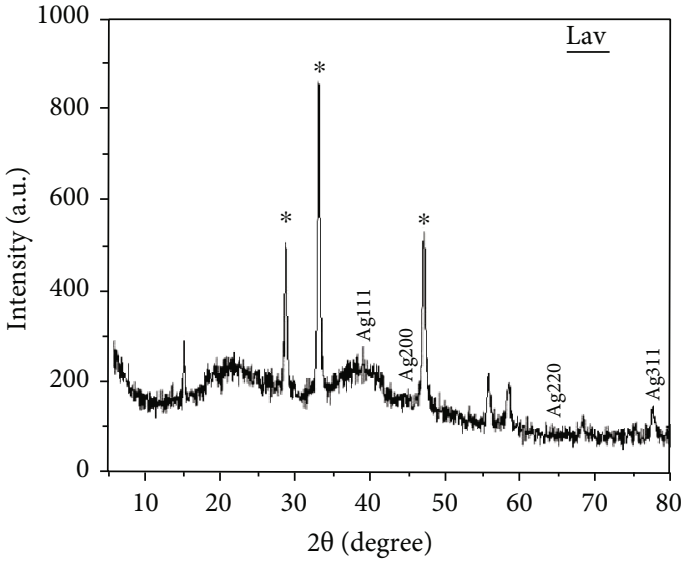

(b)

Figure 5: XRD patterns of biosynthesized Olea-AgNPs (a) and Lav-AgNPs (b).

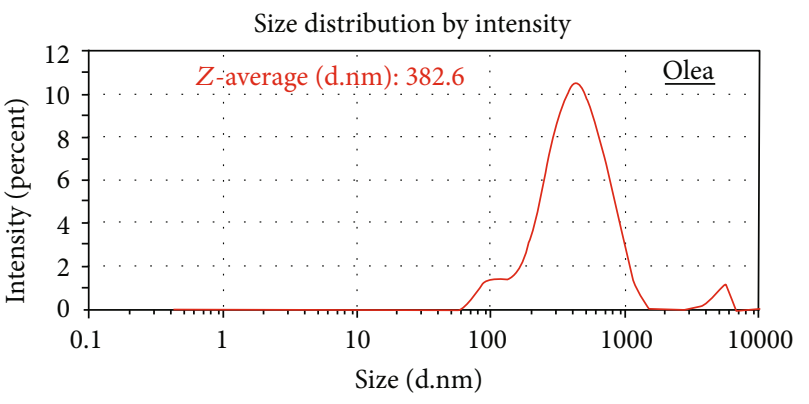

(a)

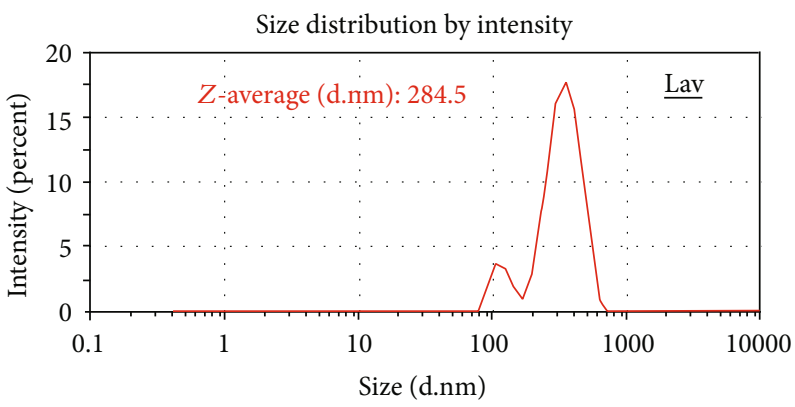

(b)

FIGURE 6: Size distribution mean of biosynthesized silver nanoparticles from Olea (a) and lavender (b) leaf extracts in nm.

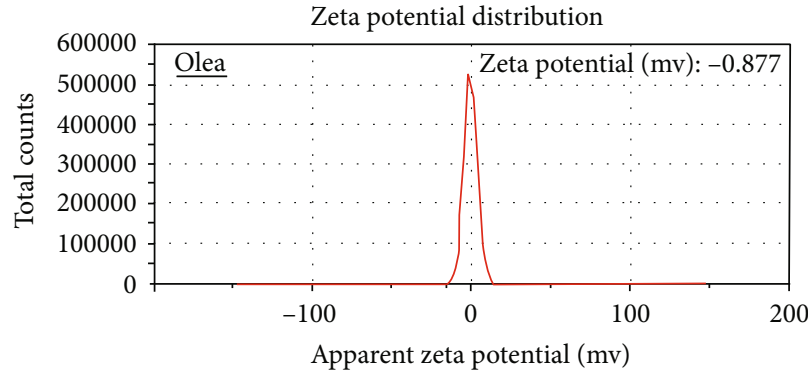

(a)

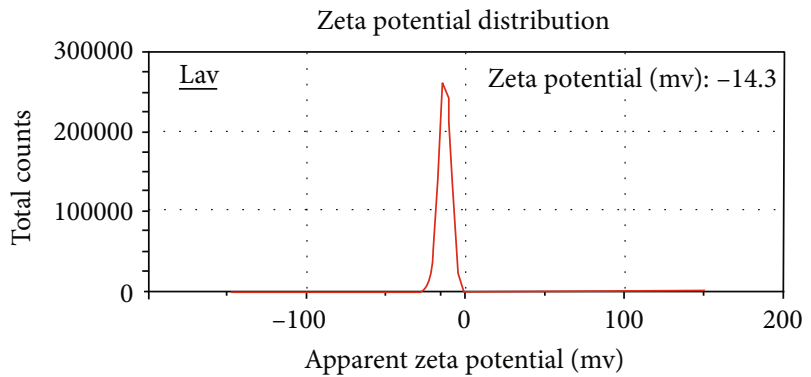

(b)

Figure 7: Zeta potential distribution of Olea-AgNPs (a) and Lav-AgNPs (b) that shows negative results in $\mathrm{mV}$.

Figures 6(a) and 6(b), respectively. Lav-AgNPs shows higher negative zeta potential $(-14.3 \mathrm{mV})$ than nanoparticles biosynthesized from Olea leaves $(-0.877 \mathrm{mV}$ ) (Figures $7(\mathrm{a})$ and $7(b))$. Mukherjee et al. reported that a high negative potential value increases negative-negative repulsion between silver nanoparticles that in turn assists their long-term stability, good colloidal nature, and high dispersity [31]. OleaAgNPs appears larger in size than those reported in previous studies that might be due to its low negativity that leads to higher attraction force and in turn leads to nanoparticle aggregation [32].
3.3. FT-IR Spectrum of Biosynthesized AgNPs from Olea and Lavender Leaf Extracts. FTIR measurement was used to determine the presence of bioactive molecules that may be responsible for silver nanoparticle stabilization via acting as capping agents. The absorption spikes at 3307, 2923, $1625,1429,1276,1182,1062,908,759$, and $551 \mathrm{~cm}^{-1}$ were determined for Olea-AgNPs, while Lav-AgNPs shows absorption spikes at $3278,2923,1581,1419,1263,1052$, 921, 586, and $530 \mathrm{~cm}^{-1}$ (Figures 8(a) and 8(b)). Higher peaks at 3307 and 3278 might be attributed to bounded hydroxyl $(-\mathrm{OH})$ of alcohols/phenols or amine $(-\mathrm{NH})$ groups 


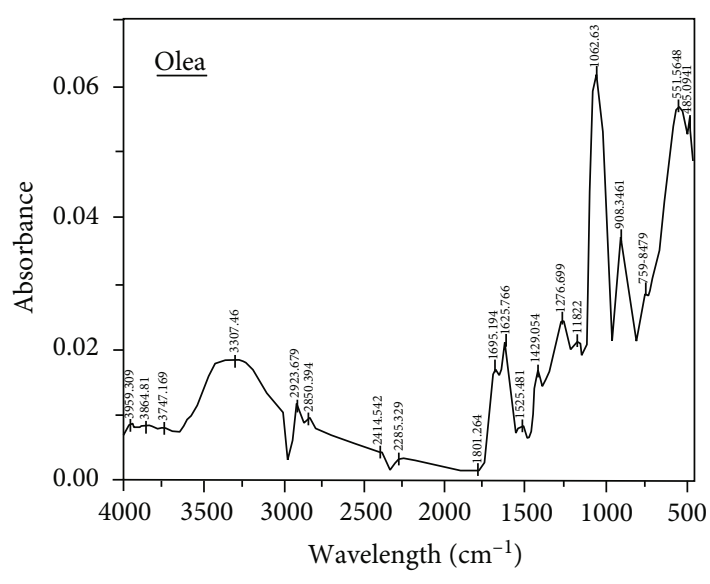

(a)

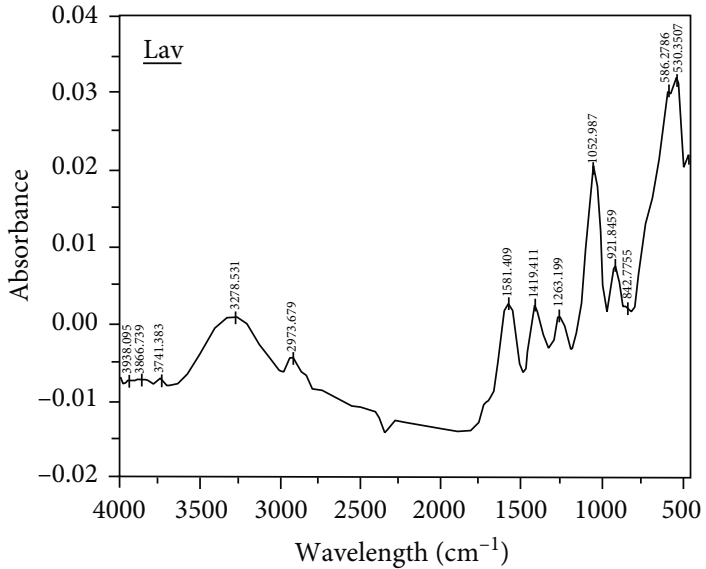

(b)

FIgURE 8: FT-IR spectra of silver nanoparticles biosynthesized using the Olea (a) and lavender (b) leaf extracts.

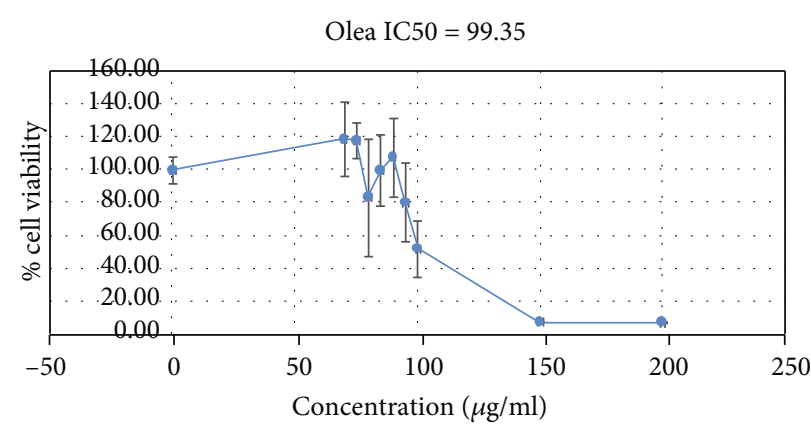

(a)

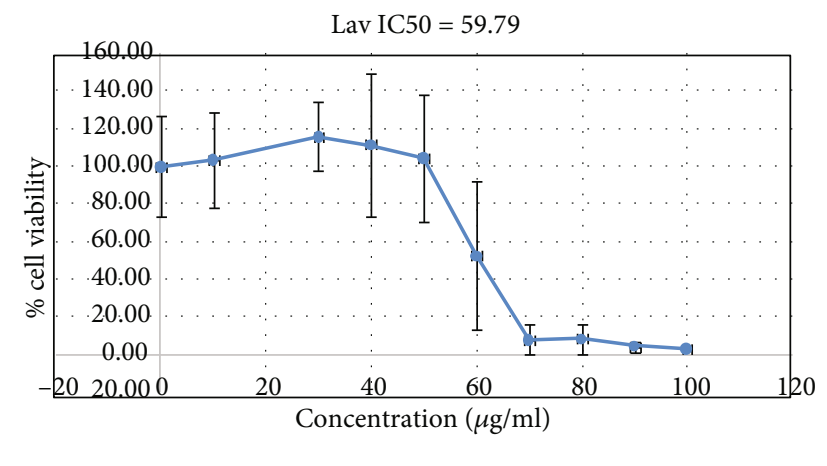

(b)

FIgURE 9: Percentage of cell viability HCT116 human colon cancer cells according to serial dilutions of Olea-AgNPs (70-200 $\mu \mathrm{g} / \mathrm{ml})(\mathrm{a})$ and Lav-AgNPs (10-100 $\mu \mathrm{g} / \mathrm{ml})$ (b).

of Olea and lavender leaf extracts, respectively. Previous studies suggested that these bonds could be due to the hydroxyl group stretching in proteins, enzymes, or polysaccharides found in their extract [33]. The presence of smaller bands at 2923 for both nanoparticle extracts was due to the $-\mathrm{CH}$ stretching of alkanes.

Peaks at $1625 \mathrm{~cm}^{-1}$ (Olea-AgNPs) and $1558 \mathrm{~cm}^{-1}$ (LavAgNPs) might be due to amide I and amide II that arise via carbonyl and $-\mathrm{N}-\mathrm{H}$ stretch vibrations in the amide linkages of proteins, respectively. The band at $1429 \mathrm{~cm}^{-1}$ (OleaAgNPs) and $1419 \mathrm{~cm}^{-1}$ (Lav-AgNPs) corresponds to the $\mathrm{C}-\mathrm{O}-\mathrm{H}$ group. The peaks at $1276 \mathrm{~cm}^{-1}$ and $1049.20 \mathrm{~cm}^{-1}$ (Olea-AgNPs) and $1263 \mathrm{~cm}^{-1}$ and $1052 \mathrm{~cm}^{-1}$ (Lav-AgNPs) attributed to $\mathrm{C}-\mathrm{O}$ stretching of esters or $\mathrm{C}-\mathrm{N}$ stretching vibrations of amines that were found in their leaf extract.

Lower bands at $551 \mathrm{~cm}^{-1}$ (Olea-AgNPs) and 586 and $530 \mathrm{~cm}^{-1}$ (Lav-AgNPs) are suggested to be due to alkyl halides such as $\mathrm{C}-\mathrm{Cl}$ stretching found in anthocyanin flavonoids that is present in those leaves' extracts [34]. Moreover, Olea and lavender contain gallic acid (phenolic flavonoids). Therefore, free groups present in the proteins and flavonoids, such as anthocyanins and gallic acid, found in plant leaf extracts were responsible for silver nitrate reduction to silver nanoparticle and capping nanoparticles for stabilization and prevent their aggregation in the medium.

3.4. Antiproliferative Potential of AgNPs on HCT116 Cells. SRB assay determined the cytotoxic effect of Olea-AgNPs $(70-200 \mu \mathrm{g} / \mathrm{ml})$ and Lav-AgNPs $(10-100 \mu \mathrm{g} / \mathrm{ml})$ by decreasing the cell viability of HCT116 colon cancer cells with different serial dilutions (Figures 9(a) and 9(b)). The half maximal inhibitory concentration (IC50) was evaluated to determine the effectiveness of silver nanoparticles in inhibiting biological or biochemical functions. Lav-AgNPs shows a higher cytotoxic effect on HCT116 cells with low concentrations $(\mathrm{IC} 50=59.79 \mu \mathrm{g} / \mathrm{ml}) \quad$ than Olea-AgNPs $\quad(\mathrm{IC} 50=99.35$ $\mu \mathrm{g} / \mathrm{ml})$ that might be due to the plant components capped to the AgNPs [35]. The present results were in agreement with previous studies that show the in vitro cytotoxic effect of biosynthesized AgNPs using different plant extracts such as Annona squamosa against the breast cancer MCF-7 cell line, Piper longum on Hep-2 cancer cell line [36], and Morinda citrifolia against HeLa cell lines [37]. The antiproliferative effects could be through the FMS-like tyrosine kinase 3 


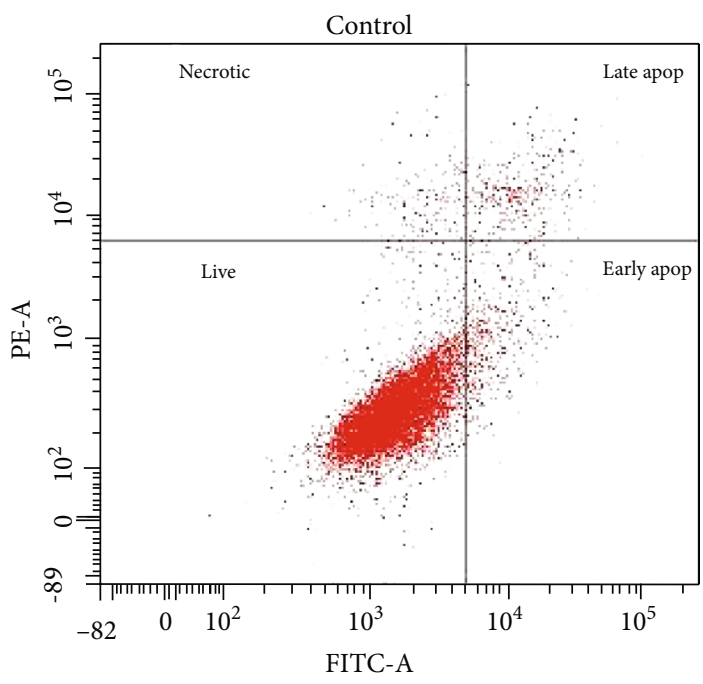

(a)

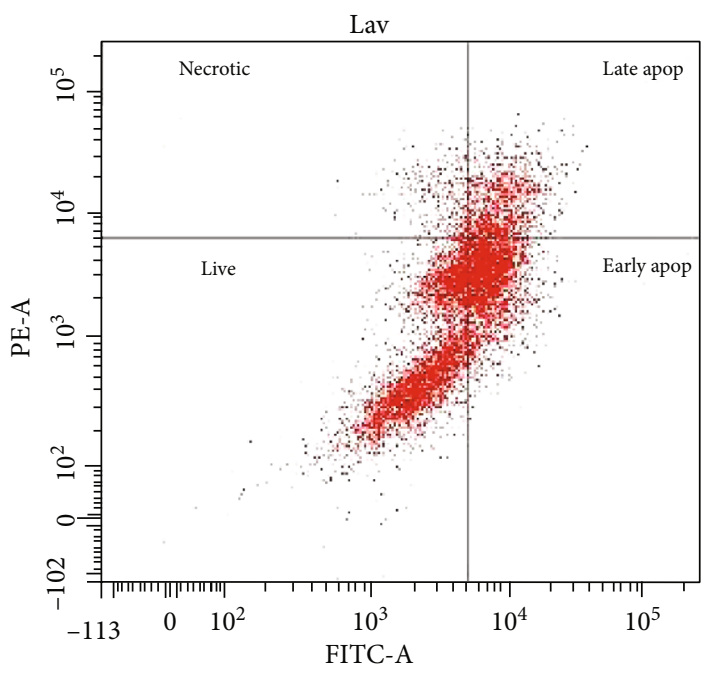

(c)

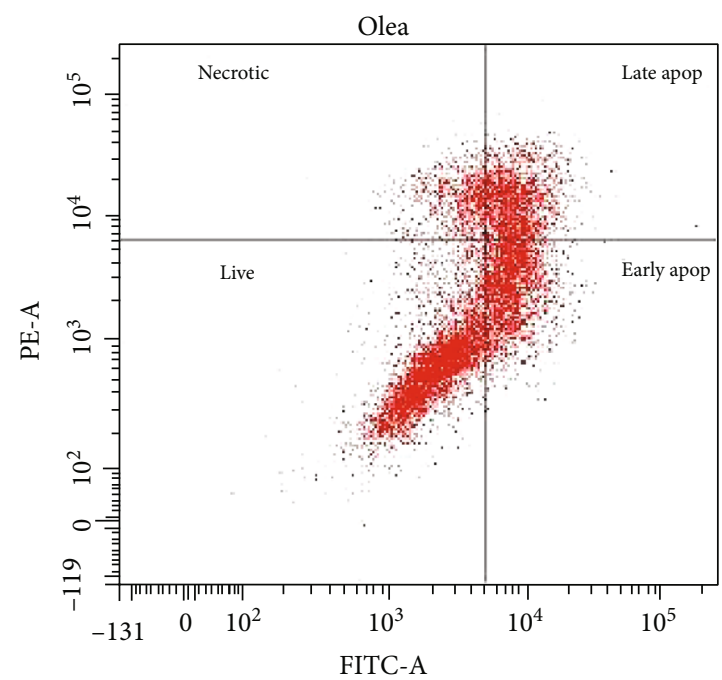

(b)

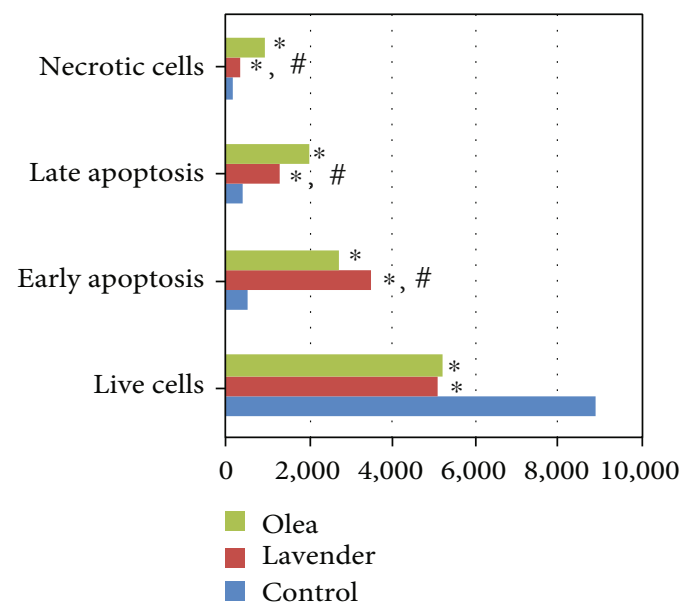

(d)

Figure 10: Flow cytometry studies on the effect of Olea-AgNPs (b) and Lav-AgNPs (c) on HCT116 cell line, in which (a) represents control untreated cells and (d) represents statistical comparison between different groups. ${ }^{*}$ Statistically compared with the negative control group. \# Olea-AgNPs-treated group statistically compared with the Lav-AgNPs-treated group.

(FLT3) pathway which has an important role in cellular proliferation, survival, and differentiation [38].

3.5. Flow Cytometry. Sex steroid induced apoptosis in breast and prostate cancer [39, 40]. Apoptotic cells have morphological and biochemical changes with chromatin fragmentation and cytoplasm shrinkage that in turn leads to the absence of membrane asymmetry. As a result, phosphatidylserine (PS) of membrane phospholipids was left behind on a plasma membrane's outer leaflet. Annexin $\mathrm{V}$ was used to detect the presence of PS on the cell membrane, and propidium iodide stains the dead cells due to its tight binding to the cell nucleic acid [41, 42]. Figures $10(\mathrm{~b})$ and $10(\mathrm{c})$ show the apoptotic potential of
IC50 concentration of Olea-AgNPs $(99.35 \mu \mathrm{g} / \mathrm{ml})$ and LavAgNPs $(59.79 \mu \mathrm{g} / \mathrm{ml})$ on HCT116 cells, respectively, while Figure 10(a) shows untreated HCT116 control cells. It is reported that live cells significantly decreased to the half by the treatment with IC50 of both silver nanoparticles and increased the apoptotic (at early and late stage) and necrotic cells in comparison to control cells (Figure 10(d)). However, Olea-AgNPs significantly increased the late stage of apoptotic cells and necrotic cells in comparison to LavAgNPs-treated cells. The present results are in well accordance with previous studies that have reported cell death due to apoptosis as a result of nanoparticle exposure [43] and green synthesized silver nanoparticles from plant extract [44]. They concluded that DNA damage and in turn apoptosis/necrosis 
are linked to excessive production of reactive oxygen species, oxidative stress [45], and SubG1 arrest of cells due to nanoparticle treatment for cancer cells [44].

\section{Conclusion}

The present study succeeds to green synthesis silver nanoparticles using an eco-friendly and low-cost method. Here, Olea chrysophylla and Lavandula dentata leaf extracts act as reducing, capping, and stabilizing agents to produce silver nanoparticles. The biosynthesized Olea-AgNPs and LavAgNPs were characterized by using SEM, XRD, DLS-zeta potential, and FTIR analysis. The present study revealed their crystalline shape with a size distribution mean of $284.5 \mathrm{~nm}$ for Lav-AgNPs and $328.6 \mathrm{~nm}$ for Olea-AgNPs; moreover, Lav-AgNPs shows more negative zeta potential than OleaAgNPs. The biosynthesized silver nanoparticles were found to have an antiproliferative potential on human colon cancer cells: HCT 116 with IC50 $=59.79 \mu \mathrm{g} / \mathrm{ml}$ for Lav-AgNPs and IC50 $=99.35 \mu \mathrm{g} / \mathrm{ml}$ for Olea-AgNPs. However, silver nanoparticles biosynthesized from Olea leaf extract show a significant apoptotic and necrotic effect on HCT116 cells than those synthesized by lavender leaf extract. In conclusion, flavonoids and proteins present in the Olea chrysophylla and Lavandula dentata leaf extracts play an important role in silver nanoparticle formation.

\section{Data Availability}

All the data used to support the findings of this study are included within the article.

\section{Conflicts of Interest}

The authors declare that they have no conflicts of interest.

\section{Authors' Contributions}

NMAS collected the plants and conducted the experiments. $\mathrm{NAH}$ and $\mathrm{YMH}$ performed the data analysis. All authors participated in writing the manuscript.

\section{Acknowledgments}

NMA and NAH would like to thank the Taif University and Cairo University. YH would like to thank King Faisal Specialist Hospital and Research Center, Jeddah, for their technical help. Special thanks are due to Dr. Emily Heaphy for editing the manuscript.

\section{References}

[1] J. Ferlay, M. Colombet, I. Soerjomataram et al., "Estimating the global cancer incidence and mortality in 2018: GLOBOCAN sources and methods," International Journal of Cancer, vol. 144, no. 8, pp. 1941-1953, 2019.

[2] F. Karimi, A. F. Shojaei, K. Tabatabaeian, H. Karimi-Maleh, and S. Shakeri, "HSA loaded with CoFe2O4/MNPs as a highefficiency carrier for epirubicin anticancer drug delivery," IET Nanobiotechnology, vol. 12, no. 3, pp. 336-342, 2018.
[3] A. Semlali, M. Almutairi, M. Rouabhia et al., "Novel sequence variants in the TLR6 gene associated with advanced breast cancer risk in the Saudi Arabian population," PLoS One, vol. 13, no. 11, article e0203376, 2018.

[4] Y. M. Hawsawi, F. al-Zahrani, C. H. Mavromatis, M. A. Baghdadi, S. Saggu, and A. A. A. Oyouni, "Stem cell applications for treatment of cancer and autoimmune diseases: its promises, obstacles, and future perspectives," Technology in Cancer Research \& Treatment, vol. 17, article 153303381880691, 2018.

[5] S. D. Markowitz and M. M. Bertagnolli, "Molecular origins of cancer: molecular basis of colorectal cancer," The New England Journal of Medicine, vol. 361, no. 25, pp. 2449-2460, 2009.

[6] A. Semlali, N. R. Parine, N. S. Al-Numair et al., "Potential role of Toll-like receptor 2 expression and polymorphisms in colon cancer susceptibility in the Saudi Arabian population," OncoTargets and Therapy, vol. 11, pp. 8127-8141, 2018.

[7] Y. Hawsawi, R. El-Gendy, C. Twelves, V. Speirs, and J. Beattie, "Insulin-like growth factor - Oestradiol crosstalk and mammary gland tumourigenesis," Biochimica et Biophysica Acta (BBA) - Reviews on Cancer, vol. 1836, no. 2, pp. 345-353, 2013.

[8] P. Renner, S. Milazzo, J. P. Liu, M. Zwahlen, J. Birkmann, and M. Horneber, "Primary prophylactic colony-stimulating factors for the prevention of chemotherapy-induced febrile neutropenia in breast cancer patients," Cochrane Database of Systematic Reviews, vol. 10, article CD007913, 2012.

[9] Y. Hawsawi, M. P. Humphries, A. Wright et al., "Deregulation of IGF-binding proteins -2 and -5 contributes to the development of endocrine resistant breast cancer in vitro," Oncotarget, vol. 7, no. 22, pp. 32129-32143, 2016.

[10] Y. M. Hawsawi, N. S. Al-Numair, T. M. Sobahy et al., "The role of BRCA $1 / 2$ in hereditary and familial breast and ovarian cancers," Molecular Genetics \& Genomic Medicine, vol. 7, no. 9, article e879, 2019.

[11] K. B. Narayanan and N. Sakthivel, "Biological synthesis of metal nanoparticles by microbes," Advances in Colloid and Interface Science, vol. 156, no. 1-2, pp. 1-13, 2010.

[12] S. F. Adil, M. E. Assal, M. Khan, A. al-Warthan, M. R. H. Siddiqui, and L. M. Liz-Marzan, "Biogenic synthesis of metallic nanoparticles and prospects toward green chemistry," Dalton Transactions, vol. 44, no. 21, pp. 9709-9717, 2015.

[13] M. Ali, B. Kim, K. D. Belfield, D. Norman, M. Brennan, and G. S. Ali, "Green synthesis and characterization of silver nanoparticles using Artemisia absinthium aqueous extract - a comprehensive study," Materials Science \& Engineering: C, vol. 58, pp. 359-365, 2016.

[14] P. Moteriya and S. Chanda, "Synthesis and characterization of silver nanoparticles using Caesalpinia pulcherrima flower extract and assessment of their in vitro antimicrobial, antioxidant, cytotoxic, and genotoxic activities," Artificial Cells, Nanomedicine, and Biotechnology, vol. 45, no. 8, pp. 1556$1567,2017$.

[15] A. K. Jha, K. Prasad, K. Prasad, and A. R. Kulkarni, "Plant system: nature's nanofactory," Colloids and Surfaces B: Biointerfaces, vol. 73, no. 2, pp. 219-223, 2009.

[16] K. N. Thakkar, S. S. Mhatre, and R. Y. Parikh, "Biological synthesis of metallic nanoparticles," Nanomedicine-Nanotechnology Biology and Medicine, vol. 6, no. 2, pp. 257-262, 2010.

[17] J. A. Jacob, N. Biswas, T. Mukherjee, and S. Kapoor, "Effect of plant-based phenol derivatives on the formation of $\mathrm{Cu}$ and $\mathrm{Ag}$ nanoparticles," Colloids and Surfaces B: Biointerfaces, vol. 87, no. 1, pp. 49-53, 2011. 
[18] H. M. Al-Yasi, S. S. Alotaibi, Y. M. Al-Sodany, and T. M. Galal, "Plant distribution and diversity along altitudinal gradient of Sarrawat Mountains at Taif Province, Saudi Arabia," Bioscience Research, vol. 16, no. 2, pp. 1198-1213, 2019.

[19] G. Besnard and A. Bervillé, "Multiple origins for Mediterranean olive (Olea europaea L. ssp. europaea) based upon mitochondrial DNA polymorphisms," Comptes Rendus de l'Académie des Sciences - Series III - Sciences de la Vie, vol. 323, no. 2, pp. 173-181, 2000.

[20] G. Besnard and A. Berville, "On chloroplast DNA variations in the olive (Olea europaea L.) complex: comparison of RFLP and PCR polymorphisms," Theoretical and Applied Genetics, vol. 104, no. 6-7, pp. 1157-1163, 2002.

[21] Z. Noormohammadi, H. Samadi-Molayousefi, and M. Sheidai, "Intra-specific genetic diversity in wild olives (Olea europaea ssp cuspidata) in Hormozgan Province, Iran," Genetics and Molecular Research, vol. 11, no. 1, pp. 707-716, 2012.

[22] L. Zhang, A. S. Ravipati, S. R. Koyyalamudi et al., "Antioxidant and anti-inflammatory activities of selected medicinal plants containing phenolic and flavonoid compounds," Journal of Agricultural and Food Chemistry, vol. 59, no. 23, pp. 1236112367, 2011.

[23] J. Y. Wong, P. Matanjun, Y. B. Ooi, and K. F. Chia, "Characterization of phenolic compounds, carotenoids, vitamins and antioxidant activities of selected Malaysian wild edible plants," International Journal of Food Sciences and Nutrition, vol. 64, no. 5, pp. 621-631, 2013.

[24] A. Pandey, T. Belwal, S. Tamta, I. D. Bhatt, and R. S. Rawal, "Phenolic compounds, antioxidant capacity and antimutagenic activity in different growth stages of in vitro raised plants of Origanum vulgare L," Molecular Biology Reports, vol. 46, no. 2, pp. 2231-2241, 2019.

[25] R. S. Farag, G. S. El-Baroty, and A. M. Basuny, "Safety evaluation of olive phenolic compounds as natural antioxidants," International Journal of Food Sciences and Nutrition, vol. 54, no. 3, pp. 159-174, 2003.

[26] V. Hajhashemi, A. Ghannadi, and B. Sharif, "Anti-inflammatory and analgesic properties of the leaf extracts and essential oil of Lavandula angustifolia Mill," Journal of Ethnopharmacology, vol. 89, no. 1, pp. 67-71, 2003.

[27] G. M. Sulaiman, A. T. Tawfeeq, and M. D. Jaaffer, "Biogenic synthesis of copper oxide nanoparticles using olea europaea leaf extract and evaluation of their toxicity activities: an in vivo and in vitro study," Biotechnology Progress, vol. 34, no. 1, pp. 218-230, 2018.

[28] M. Karg, S. Jaber, T. Hellweg, and P. Mulvaney, "Surface plasmon spectroscopy of gold-poly-N-isopropylacrylamide coreshell particles," Langmuir, vol. 27, no. 2, pp. 820-827, 2011.

[29] V.S. Suvith and D. Philip, "Catalytic degradation of methylene blue using biosynthesized gold and silver nanoparticles," Spectrochimica Acta Part A: Molecular and Biomolecular Spectroscopy, vol. 118, pp. 526-532, 2014.

[30] J. M. D. Marković, J. M. Baranac, and T. P. Brdarić, "Electronic and infrared vibrational analysis of cyanidin-quercetin copigment complex," Spectrochimica Acta Part A: Molecular and Biomolecular Spectroscopy, vol. 62, no. 1-3, pp. 673-680, 2005.

[31] S. Mukherjee, D. Chowdhury, R. Kotcherlakota et al., "Potential theranostics application of bio-synthesized silver nanoparticles (4-in-1 system)," Theranostics, vol. 4, no. 3, pp. 316-335, 2014.
[32] M. Ovais, A. T. Khalil, A. Raza et al., "Green synthesis of silver nanoparticles via plant extracts: beginning a new era in cancer theranostics," Nanomedicine, vol. 11, no. 23, pp. 3157-3177, 2016.

[33] C. Mohandass, A. S. Vijayaraj, R. Rajasabapathy et al., "Biosynthesis of silver nanoparticles from marine seaweed Sargassum cinereum and their antibacterial activity," Indian Journal of Pharmaceutical Sciences, vol. 75, no. 5, pp. 606-610, 2013.

[34] B. Ajitha, Y. A. K. Reddy, and P. S. Reddy, "Biogenic nanoscale silver particles by Tephrosia purpurea leaf extract and their inborn antimicrobial activity," Spectrochimica Acta Part A: Molecular and Biomolecular Spectroscopy, vol. 121, pp. 164-172, 2014.

[35] M. A. Farah, M. A. Ali, S. M. Chen et al., "Silver nanoparticles synthesized from Adenium obesum leaf extract induced DNA damage, apoptosis and autophagy via generation of reactive oxygen species," Colloids and Surfaces B: Biointerfaces, vol. 141, pp. 158-169, 2016.

[36] S. J. Jacob, J. S. Finub, and A. Narayanan, "Synthesis of silver nanoparticles using Piper longum leaf extracts and its cytotoxic activity against Hep-2 cell line," Colloids and Surfaces B: Biointerfaces, vol. 91, pp. 212-214, 2012.

[37] T. Y. Suman, S. R. Radhika Rajasree, A. Kanchana, and S. B. Elizabeth, "Biosynthesis, characterization and cytotoxic effect of plant mediated silver nanoparticles using Morinda citrifolia root extract," Colloids and Surfaces B: Biointerfaces, vol. 106, pp. 74-78, 2013.

[38] R. El Fakih, W. Rasheed, Y. Hawsawi, M. Alsermani, and M. Hassanein, "Targeting FLT3 mutations in acute myeloid leukemia," Cell, vol. 7, no. 1, p. 4, 2018.

[39] P. Y. Maximov, B. Abderrahman, R. F. Curpan, Y. M. Hawsawi, P. Fan, and V. C. Jordan, "A unifying biology of sex steroid-induced apoptosis in prostate and breast cancers," Endocrine-Related Cancer, vol. 25, no. 2, pp. R83-R113, 2018.

[40] V. C. Jordan, P. Fan, B. Abderrahman et al., "Sex steroid induced apoptosis as a rational strategy to treat antihormone resistant breast and prostate cancer," Discovery Medicine, vol. 21, no. 117, pp. 411-427, 2016.

[41] L. F. Lincz, "Deciphering the apoptotic pathway: all roads lead to death," Immunology and Cell Biology, vol. 76, no. 1, pp. 1-19, 1998.

[42] A. M. Rieger and D. R. Barreda, "Accurate assessment of cell death by imaging flow cytometry," Methods in Molecular Biology, vol. 1389, pp. 209-220, 2016.

[43] Y. Pan, S. Neuss, A. Leifert et al., "Size-dependent cytotoxicity of gold nanoparticles," Small, vol. 3, no. 11, pp. 1941-1949, 2007.

[44] E. S. Al-Sheddi, N. N. Farshori, M. M. Al-Oqail et al., "Anticancer potential of green synthesized silver nanoparticles using extract of Nepeta deflersiana against human cervical cancer cells (HeLA)," Bioinorganic Chemistry and Applications, vol. 2018, Article ID 9390784, 12 pages, 2018.

[45] Y. H. Hsin, C. F. Chen, S. Huang, T. S. Shih, P. S. Lai, and P. J. Chueh, "The apoptotic effect of nanosilver is mediated by a ROS- and JNK-dependent mechanism involving the mitochondrial pathway in NIH3T3 cells," Toxicology Letters, vol. 179, no. 3, pp. 130-139, 2008. 


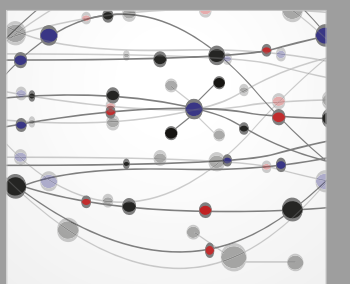

The Scientific World Journal
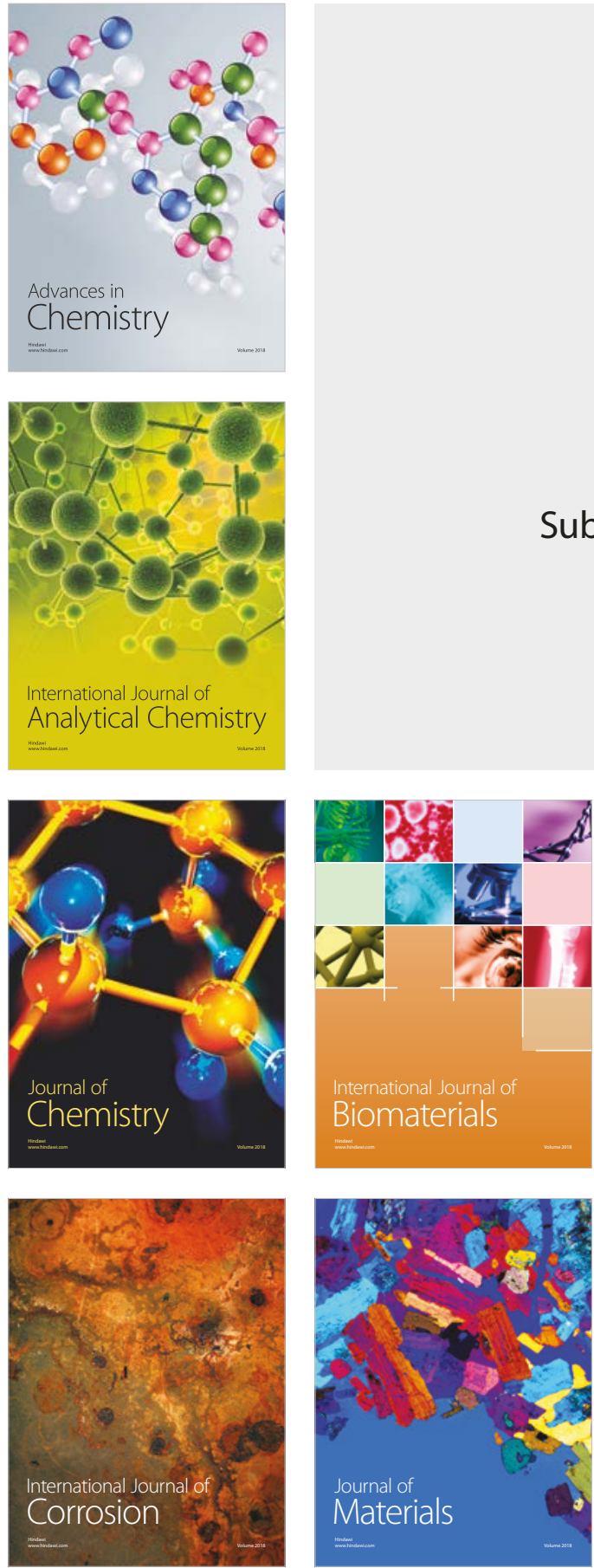

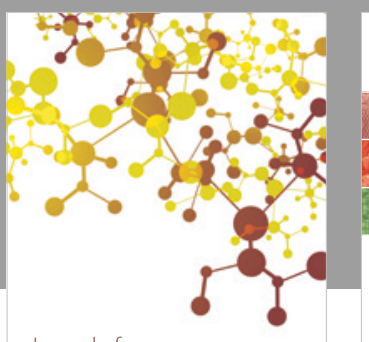

Journal of

Applied Chemistry
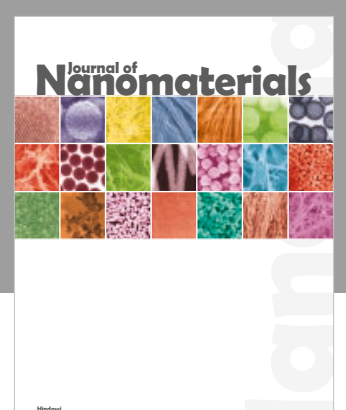

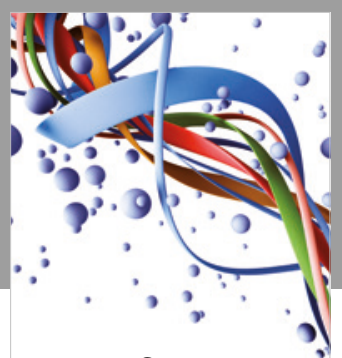

Scientifica

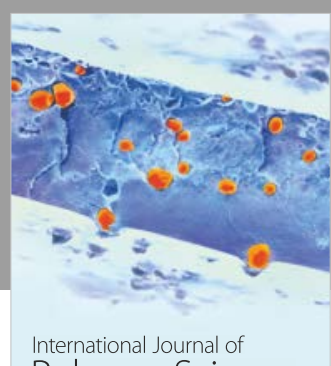

Polymer Science

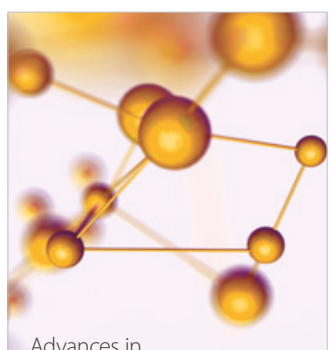

Physical Chemistry
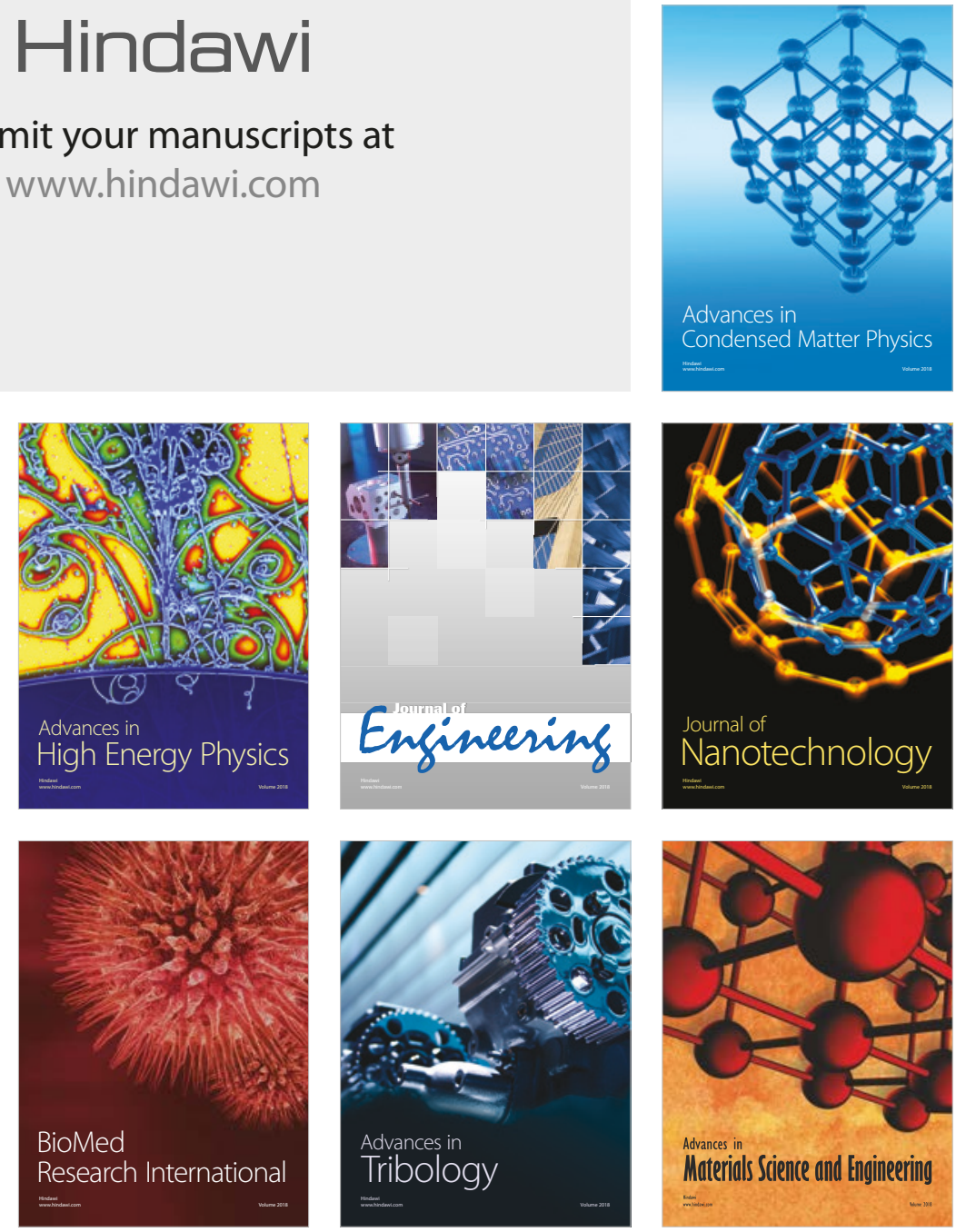